Relations industrielles

Industrial Relations

\title{
Labor in the United States, by Sanford Cohen. Charles E. Merrill Books, Inc., Columbus, Ohio. 1960. 675 pages.
}

\section{Gérard Dion}

Volume 18, numéro 3, juillet 1963

URI : https://id.erudit.org/iderudit/1021414ar

DOI : https://doi.org/10.7202/1021414ar

Aller au sommaire du numéro

Éditeur(s)

Département des relations industrielles de l’Université Laval

ISSN

0034-379X (imprimé)

1703-8138 (numérique)

Découvrir la revue

Citer ce compte rendu

Dion, G. (1963). Compte rendu de [Labor in the United States, by Sanford Cohen. Charles E. Merrill Books, Inc., Columbus, Ohio. 1960. 675 pages.] Relations industrielles / Industrial Relations, 18(3), 430-430.

https://doi.org/10.7202/1021414ar

Tous droits réservés (C Département des relations industrielles de l’Université Laval, 1963
Ce document est protégé par la loi sur le droit d'auteur. L'utilisation des services d'Érudit (y compris la reproduction) est assujettie à sa politique d'utilisation que vous pouvez consulter en ligne.

https://apropos.erudit.org/fr/usagers/politique-dutilisation/ 
Relations IndUSTRIELLES, vol. 18 , No 3

ner les autres ò accepter des revendications ou ò régler un litige. L'essai de classification que fait l'auteur dénote un bel effort de synthèse, mais il pourrait être plus complet. On voit qu'il s'en tient surtout à l'expérience de son propre pays.

L'auteur, dans son ouvrage, foit montre d'une bonne érudition. II a pris connaissance de la plupart des travaux publiés sur le sujet et la bibliographie que contient un des annexes est assez vaste. Nous regrettons cependant que lui ait échappé une étude de Von Nell-Breuning intitulée $<\mathrm{Im}$ plications politiques de la grève » que publiait en 1956 la Revue de l'Action populaire. A notre sens, les considérations de l'éminent professeur allemand sont tout à fait fondamentales dans toute étude sur la grève.

La grève, phénomène de civilisation est un ouvrage sérieux qui enrichit la littérature sur un sujet oussi importont qui n'a pas fini d'attirer l'attention des sociologues, des économistes et des juristes.

Gérord DION

Stabilité du Personnel dans les Hôpitaux du Québec, Rapports no 1 et no 2, Conseil de Recherche de l'Ecole Supérieure d'Administration Hospitalière du Comité des Hôpitaux du Québec, miméographié 70 pages et 108 pages, 1963.

Le premier rapport analyse l'ancienneté du personnel, le second analyse les causes de départ des salariés à l'emploi des hôpitaux.

\section{Jacques ST-LAURENT}

The Anvil and the Plow, U.S. Department of Labor, Office of Information, Publications, and Reports, 1963, 302 pages.

L'histoire du Ministère du Travail américain rédigée à l'occosion de son cinquantième anniversaire. C'est un rappel des changements majeurs survenus dans le monde ouvrier américain depuis 1913 et de la façon dont le Ministère du Travail s'est odapté à une société en continuelle évolution.

\section{Jacques ST-LAURENT}

Labor in the United States, by Sanford Cohen. Charles E. Merrill Books, Inc., Columbus, Ohio. 1960. 675 pages.

Cet ouvrage veut être une introduction à l'étude des problèmes des relations du travail pour le bénéfice des étudiants et aussi des personnes engagées dans ce domaine. L'approche de l'auteur est interdisciplinaire. C'est pourquoi on $y$ trouvera de I'histoire, de la sociologie, du droit, de l'économique et des sciences politiques.

L'outeur, qui enseigne depuis longtemps cette matière, maîtrise bien son sujet et ne cherche pas à faire oeuvre scientifique. II a divisé son étude en sept parties: Lo main d'oeuvre oux Etats-Unis, le syndicalisme oux Etots-Unis, la négociation collective; I'analyse des solaires; la législation du travail; le problème de I'insécurité économique; conclusion. A la fin de chaque chapitre, on trouve une série de questions pour les étudionts et une très courte bibliographie. Comme on peut s'en rendre compte, tout est centré sur des données américaines. C'est un bon manuel pour étudiants américains bien qu'on puisse regretter que l'auteur n'ait pas songé à les aider à prendre conscience que les Etats-Unis ne sont pos à eux seuls l'univers. Comment, en effet, bien comprendre même les problèmes américains sans tenir compte de l'interdépendance des économies et de I'influence des idéologies étrangères?

Malgré cette restriction, nous considérons que l'auteur, dont les jugements sont pondérés et honnêtes, o rendu service aux étudiants et oux professeurs en mettant entre leurs mains un ouvrage acceptable.

Gérard DION

《Introduction to Social Welfare 》 (deuxième édition) par Walter A. Friedlander, Prentice Hall, Englewood Cliffs, N.J., 1961, 589 poges.

Cette révision complète et soignée tient compte des nombreux commentaires de centaines d'utilisateurs de la première édition parue en 1955. Ce volume explique comment les services et les concepts de bien-être social se sont développés à travers la tradition, l'expérience et le changement sociologique. II analyse dans une perspective historique et philosophique, le système complexe présent de bien-être social, ses principes, son cadre légal et ses effets sur les membres de notre société.

Selon l'auteur lui-même, ce livre s'adresse particulièrement à trois groupes de lecteurs: (1) ceux qui projettent de travailler, ou qui travaillent déjò, dans les domaines de l'assistance publique, de la récréation etc., (2) ceux intéressés d'une façon ou d'une autre aux études de service social, etc et 